\title{
Sentinel node lymphocytes: tumour reactive lymphocytes identified intraoperatively for the use in immunotherapy of
} colon cancer

\author{
P Marits ${ }^{1,2,5}$, M Karlsson ${ }^{1,2,5}, K_{\text {Dahl }}^{3}$, P Larsson', A Wanders ${ }^{4}$, M Thörn ${ }^{3}$ and O Winqvist ${ }^{* 1,2}$ \\ 'Department of Internal Medicine, Uppsala University Hospital, Uppsala University, 75 I 85 Uppsala, Sweden; ${ }^{2}$ Department of Medicine, Unit of Clinical \\ Allergy Research, Karolinska Hospital, Karolinska Institutet, 17176 Stockholm, Sweden; ${ }^{3}$ Department of Surgery, South Stockholm General Hospital, \\ Karolinska Institutet, I I 883 Stockholm, Sweden; ${ }^{4}$ Department of Pathology, Uppsala University Hospital, Uppsala University, 75 I 85 Uppsala, Sweden
}

\begin{abstract}
The sentinel node is the first lymph node to receive lymphatic drainage from a tumour and is usually the first site of metastases. Today, the sentinel node is used for tumour staging. Here, we focus on its immunological role and investigate lymphocytic function in sentinel nodes, identified intraoperatively by peritumoural dye injection, from 15 patients with colon cancer. Tumour infiltrating lymphocytes, sentinel and nonsentinel lymph node cells and peripheral blood leukocytes were studied by flow cytometry, proliferation assays and interferon- $\gamma$ secretion after activation with autologous tumour homogenate. Whereas tumour-infiltrating lymphocytes were nonresponsive in the proliferation assays, lymphocytes from sentinel nodes proliferated dose dependently and secreted interferon- $\gamma$ upon stimulation with tumour homogenate. The responses were of varying magnitude and tended to be weaker in metastatic sentinel nodes. Sentinel node lymphocytes represents an enriched source of tumour reactive lymphocytes, and may be useful in future trials of adoptive immunotherapy.

British Journal of Cancer (2006) 94, |478-|484. doi:I0.1038/sj.bjc.6603126 www.bjcancer.com
\end{abstract}

Published online 25 April 2006

(C) 2006 Cancer Research UK

Keywords: sentinel node; colon cancer; adoptive immunotherapy; tumour reactive lymphocytes

Colorectal cancer (CRC) is a major cause of morbidity worldwide, accounting for over 1 million new cases and 500000 deaths per year (Parkin et al, 2005). Surgery is the primary treatment modality and is curative in approximately $50 \%$ of patients, however, the remaining half of patients will ultimately die of metastatic disease (Obrand and Gordon, 1997). Standard, Fluorouracil-based, chemotherapy in the adjuvant setting confers at most $10 \%$ absolute increase in survival in patients with lymph node positive disease (Duke's C) (Arkenau et al, 2003), while there is no evidence for its benefit in patients with localised disease (Benson et al, 2004). Thus, there is a great need for developing alternative adjuvant treatments.

Studies of prognostic factors in colorectal cancer point out the histological status of the regional lymph nodes as the most important predictor of survival (Swanson et al, 2003) and the presence of regional lymph node metastases implies a $40-50 \%$ reduction in 5-year survival rates. The sentinel node is defined as the first lymph node, or nodes, to receive lymphatic drainage from a tumour. It can be identified during surgery by injection of a tracer substance around the tumour. The tracer is transported in the lymph capillaries and accumulates in the sentinel node(s), thus identifying the tumour draining lymph node. The histological status of the sentinel node is regarded as representative for the

\footnotetext{
*Correspondence: Dr O Winqvist; E-mail: ola.winqvist@karolinska.se

${ }^{5}$ These authors contributed equally to this work

Received 7 October 2005; revised 2 March 2006; accepted 15 March 2006; published online 25 April 2006
}

status of the entire lymphatic field. The sentinel node method, first introduced in 1977 (Cabanas, 1977), is established in malignant melanoma and breast cancer (Leong, 2004) and it has also been applied to colon cancer (Saha et al, 2000; Thörn, 2000). Recently, we demonstrated the usefulness of sentinel node detection for the staging of colon cancer (Dahl et al, 2005).

According to the immune surveillance hypothesis (Burnet, 1970), the immune system is continuously sensitised against developing tumours, most of which are eliminated at an early stage. Strong experimental evidence in favour of this notion has been presented in recent years, extensively reviewed by Dunn et al (2004). The identification of specific tumour antigens has created new possibilities for tumour immunotherapy (Rosenberg, 2001) and many immunotherapeutic approaches are now being translated into clinical trials (Ribas et al, 2003). Among these, adoptive transfer of tumour antigen-specific lymphocytes seems particularly promising. These attempts are usually based on either mononuclear cells from peripheral blood or tumour infiltrating lymphocytes (TIL) separated from fresh tumour specimens. In recent trials, treatment of patients with malignant melanoma with autologous transfer of expanded TILs, objective response rates of up to $51 \%$ has been reported (Rosenberg and Dudley, 2004). In CRC, the presence of TIL correlates with a more favourable prognosis (Giorgio et al, 1992) and TIL from CRCs, expanded in vitro in IL-2, display specific cytokine secretion in response to autologous tumour cells (Hom et al, 1993). However, TIL from several human tumours, including CRC, display reduced levels of the CD3 zeta chain (Nakagomi et al, 1993). In addition, T-cell responses to mitogenic stimulation are decreased in lymphocytes 
from the venous blood draining CRCs, as compared with lymphocytes obtained from the arterial blood supplying the tumour (Rigg et al, 1991). Thus, the limited number of TIL that can be obtained from solid tumour biopsies may not be an ideal cell population for adoptive immunotherapy.

As experimental evidence indicate that activation of naïve $\mathrm{T}$ cells occurs within the highly specialised microenvironment of secondary lymphoid organs, that is lymph nodes and spleen (Itano and Jenkins, 2003), the sentinel node may be regarded as the primary site for the immune system to encounter tumour antigens. In the present study, we take advantage of the specific sentinel node detection to investigate the immunological tumour reactivity in sentinel lymph nodes draining human colon cancers.

\section{MATERIALS AND METHODS}

\section{Patients}

Fifteen patients with colon cancer, with no signs of distant metastases or lymph node involvement prior to surgery, seven men and eight women, with an average age of 71 years were included in the study (Table 1). The study was approved by the local ethical committee and informed consent was given by the patients.

\section{Identification of sentinel nodes}

The colonic tumour site was mobilised through division of peritoneal adhesions to facilitate inspection of tumour and mesentery. One ml Patent blue dye (Guerbet, Paris) was injected superficially in the serosa around the tumour. Within $5 \mathrm{~min}$, one to four blue-coloured mesenteric lymph nodes were identified macroscopically as sentinel nodes and they were marked with sutures.

\section{Preparation of specimens}

The sentinel and nonsentinel nodes were cut in half. Slices $<1 \mathrm{~mm}$ thick were cut from the central and the peripheral part of the nodes for flow cytometry and proliferation analysis. The rest of the node underwent routine histopathological examination. Tumours were histopathologically classified as Duke's stages A-D (Duke, 1932) (Table 1). One piece of the primary tumour (including part of the invasive margin) was removed for flow cytometry analyses and as an antigen source.

\section{Flow cytometry analyses}

Peripheral blood leukocytes (PBL), lymph node cells and tumour cell suspensions at $1 \times 10^{6}$ cells sample ${ }^{-1}$ were subjected to investigation using flow cytometry (FACS). Cells were washed in PBS containing 2\% FCS and $0.05 \% \mathrm{NaN}_{3}$ and stained with fluorophore conjugated antibodies against the cell surface molecules CD4 PE, CD8 PerCp (Becton Dickinson, San Jose, CA, USA) and the very early activation marker CD69 FITC (Pharmingen, San Jose, CA, USA). After staining, cells were investigated using a FACSCalibur (Becton Dickinson) and data were analysed using the Cellquest computer software (Becton Dickinson).

\section{Immunological evaluation}

Single cell suspensions from lymph nodes and tumours were obtained by gentle pressure using a loose fit glass homogeniser. Peripheral blood leukocytes were purified by ficoll-paque (Pharmacia, Amersham, Uppsala, Sweden). Cells were resuspended and washed twice in RPMI 1640 (Life technologies, Rockville, MD, USA) containing $2.5 \%$ fetal calf serum (FCS) (Life technologies). Finally, cells were resuspended in RPMI 1640 proliferation media containing 10\% human AB serum (Sigma-Aldrich, St Louis, MO, USA), $1 \%$ penicillin-streptomycin (Sigma) and $1 \%$ glutamine (Sigma). Tumour samples were homogenised using a Ultra-turrax in $5 \mathrm{v}\left(\mathrm{w} \mathrm{v}^{-1}\right)$ of $2 \times$ PBS followed by 5 min denaturation at $97^{\circ} \mathrm{C}$. Tumour homogenates were diluted to $1: 10$ and $1: 100$ in complete proliferation media. Purified PBL and lymph node cells were used at $3 \times 10^{5}$ cells well $^{-1}$ in time course proliferation assays against diluted tumour homogenate, Con A $10 \mu \mathrm{g} \mathrm{ml}^{-1}$ (Sigma) or carcinoembryonic antigen $100 \mu \mathrm{g} \mathrm{ml}^{-1}$ (Sigma) in triplicate. Proliferation was measured by adding $1 \mu C_{\mathrm{i}}$ of ${ }^{3} \mathrm{H}$-Thymidine/well (Amersham) $18 \mathrm{~h}$ prior to harvesting. Samples were subjected to scintillation counting.

Stimulations for the measurement of IFN- $\gamma$ secretion were performed in 96-well plates with $3 \times 10^{5}$ cells well $^{-1}$ in triplicate with tumour homogenate diluted $1 / 10$ and $1 / 100$, or Con $\mathrm{A}$ $10 \mu \mathrm{g} \mathrm{ml}^{-1}$ (Sigma). The amount of secreted IFN- $\gamma$ was measured with ELISA (Human IFN- $\gamma$ Duoset, R\&D Systems) on culture supernatants in pooled samples of the triplicates.

Table I Patient characteristics, location of tumours, staging and investigated lymph nodes

\begin{tabular}{lcclcccc}
\hline Patient No & Sex & Age (year) & Tumour site & $\begin{array}{c}\text { Metastatic } \\
\text { Duke's } \\
\text { classification }\end{array}$ & $\begin{array}{c}\text { Modes/harvest } \\
\text { nodes }\end{array}$ & $\begin{array}{c}\text { No of SNs } \\
\text { obtained }\end{array}$ & $\begin{array}{c}\text { Number of cells } \\
\text { in SN ( } \times \text { I06) }\end{array}$ \\
\hline \%CD4/\%CD8
\end{tabular}

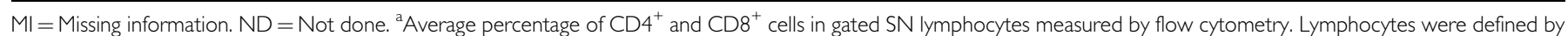
gating on forward and side scatter characteristics. 


\section{RESULTS}

\section{Intraoperative identification of sentinel node and pathological classification}

One to four sentinel nodes (average 2.3) were detected intraoperatively using Patent blue injection in the circumference of the tumour. Patient characteristics and location of the tumours are presented in Table 1. Upon macroscopical dissection of the removed specimens, between five and 29 lymph nodes (average 19) were identified and embedded for histopathological evaluation (Figure 1A and B, left panels). Nine of the patients (Table 1) showed no signs of metastatic spread to sentinel node(s), nor to other lymph nodes despite that tumours grew through the bowel muscular wall (Figure 1A left panel) and they were classified as Duke's B. Patients no 10-14 (Table 1) had metastatic spread to the sentinel node and were histopathologically classified as Duke's C (Figure 1B left panel). Between one and six metastatic lymph nodes were identified by histopathology (Table 1). Patient no 15 in addition to one metastatic sentinel node had distant metastases to the liver, found at surgery, and was consequently classified as Duke's D (Table 1).

\section{Characterisation of immune cells in sentinel nodes}

Single cell suspensions of lymphocytes collected from the tumour, sentinel and nonsentinel lymph node specimens, and peripheral blood (PBL), were prepared as described in Material and Methods. The number of sentinel nodes obtained and average cell yield from the sentinel node specimens for each patient are given in Table 1. Cell suspensions were triple stained with antibodies recognising the very early activation marker CD69 and the surface antigens CD4 (Figure 1A and B, middle panels) and CD8 (not shown) followed by flow cytometry analyses (FACS). The lymphocytic gate was established by gating on forward and side scatter characteristics. The percentage of $\mathrm{CD} 4{ }^{+}$and $\mathrm{CD}^{+}$cells in the lymphocytic gate varied between lymph nodes (Table 1). No significant correlation was found between the ratio of $\mathrm{CD}^{+}$to $\mathrm{CD}^{+}$cells and tumour stage or proliferative response (data not shown). Similar numbers of activated $\mathrm{CD} 4{ }^{+} \mathrm{CD} 69^{+}$lymphocytes were found both in sentinel and nonsentinel nodes regardless of absence (Figure 1A middle panel) or presence of metastases (Figure 1B middle panel). All investigated tumours contained tumourinfiltrating lymphocytes (TILs) to a various extent. Tumourinfiltrating lymphocytes were both of the CD4 and CD8 subsets and the majority presented an activated $\mathrm{CD} 9^{+}$phenotype. In peripheral blood activated, $\mathrm{CD} 69^{+}$lymphocytes were absent (not shown).

\section{Functional characterisation of lymphocytes}

The proliferative responses of the cell populations were characterised by time course ${ }^{3} \mathrm{H}$-Thymidine incorporation assays using homogenised denatured autologous tumour cell extracts as antigen sources (Figure 1A and B right panels and Table 2). TILs did not proliferate in any of the investigated patients. By contrast, SN lymphocytes from eight patients classified as Duke's B proliferated in an antigen dependent manner against autologous tumour extract (Figure 1A, right panel and Table 2) with an average peak proliferation of $24567 \pm 6473 \mathrm{cpm}$ (average \pm s.e.m.). Peak proliferation was most frequently observed on day 6 . In patient no 5 , thymidine incorporation was not performed. SN lymphocytes from five out of six metastatic nodes (patients no $10-12,14$ and 15) responded poorly, with an average proliferation of $2141 \pm 1002$ (average \pm s.e.m.) (Figure 1B, right panel). From one Duke's C patient (no 13) SN lymphocytes proliferated vigorously when stimulated with autologous tumour extract $(30469 \mathrm{cpm})$ and also exhibited a high spontaneous proliferation (Table 2). In addition, in two Duke's B patients the reactivity against a known colon cancer antigen, carcinoembryonic antigen (CEA) was tested. However, stimulation of SN lymphocytes with $100 \mu \mathrm{g} \mathrm{ml}^{-1}$ of CEA did not result in proliferation (data not shown). In nonsentinel nodes proliferation upon stimulation with tumour extract was not
A
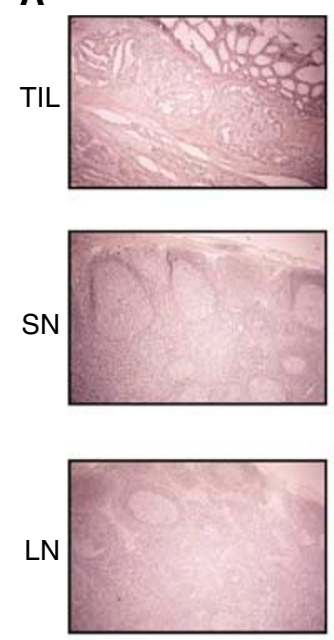

Duke's B

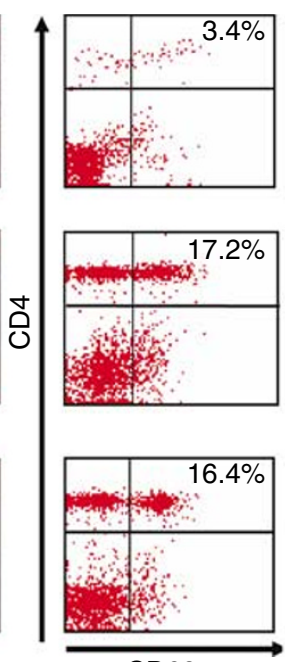

CD69

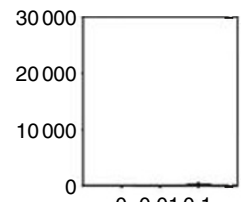

$0 \overrightarrow{0} 0.010 .1$
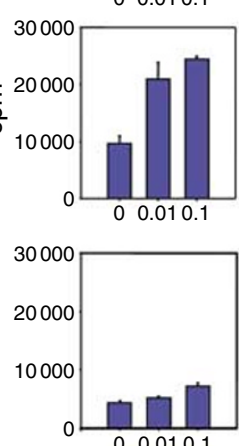

B

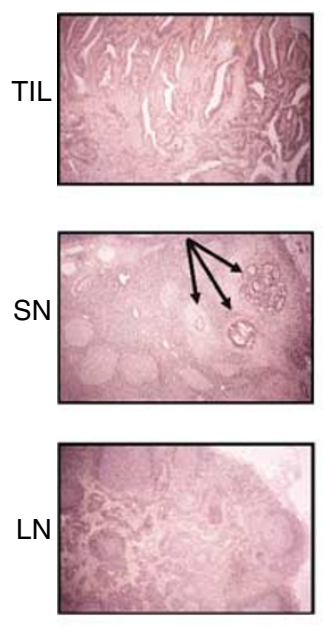

Duke's C

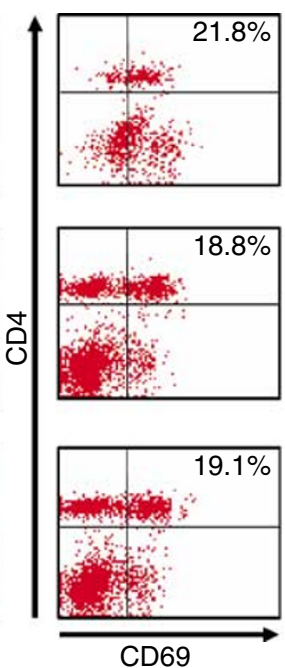

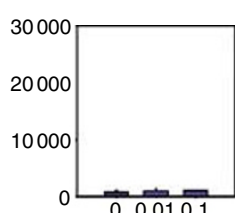
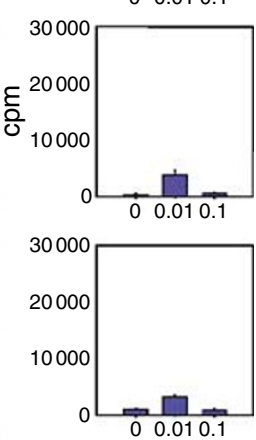

Figure I Characterisation of lymphocytes. In 15 colon cancer patients, tumour-draining, sentinel lymph nodes were identified by peritumoural injection of a blue tracer. Specimens from the tumour (CC), sentinel node (SN) and nonsentinel node $(L N)$ and stained with haematoxylin-eosin (left panels) (40 $\times$ ). Data from patient no I with a Duke's B tumour $(\mathbf{A})$ and patient no 12 with Duke's C (B). Arrows indicate the presence of metastatic colon cancer cells in a sentinel node (B, left panel, SN). Single cell suspensions from the specimens were stained with antibodies against CD4 and the activation marker CD69 and analysed using flow cytometry (middle panels), the percentage of double positive activated CD4 T-helper cells are indicated in the upper right corner. Cell suspensions in triplicates were incubated with a 10- and 100 -fold dilutions of autologous tumour homogenate in a day 5-7 proliferation assay. Cells were pulsed $18 \mathrm{~h}$ before harvesting with $\mathrm{I} \mu \mathrm{C}_{\mathrm{i}} 3 \mathrm{H}$-Thymidine. Proliferation data from day $5(\mathbf{A})$ and day $6(\mathbf{B})$, respectively, are shown. Error bars indicate s.e.m. (right panels). 
Table 2 Proliferative responses in lymphocytes from sentinel node, the tumour, nonsentinel node and peripheral blood upon stimulation with autologous tumour extract

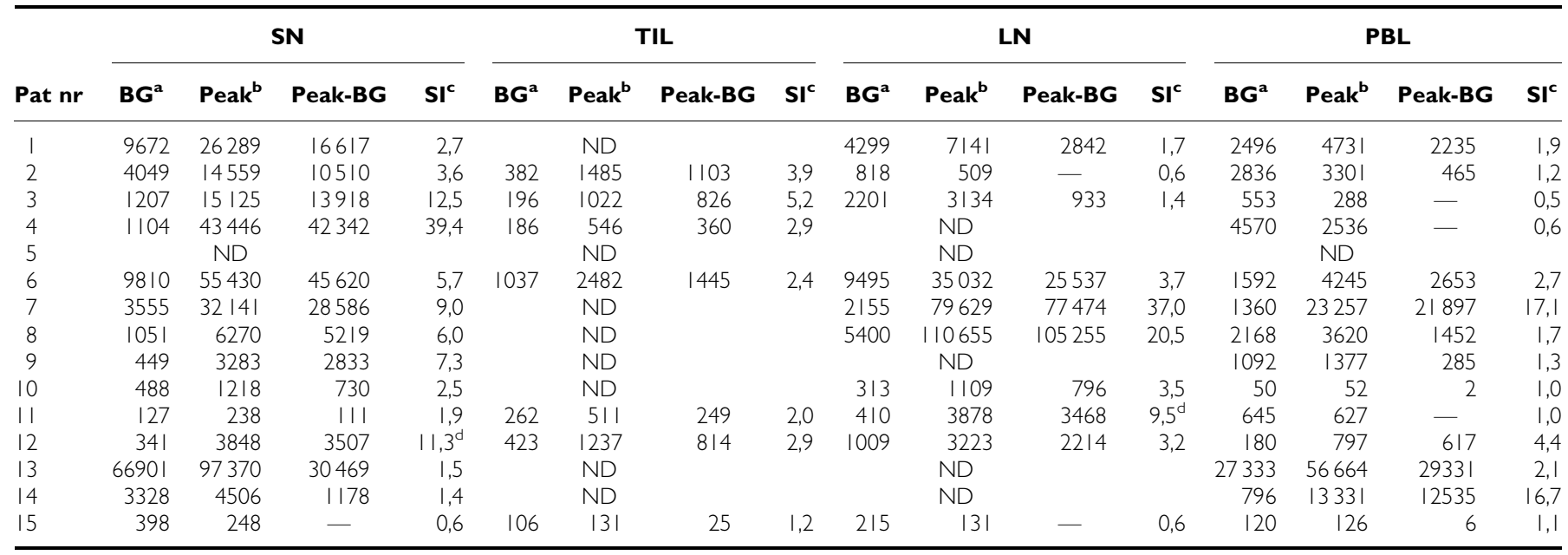

All values are given in counts per minute (cpm) except the Stimulation Index (SI). SN, sentinel node; TIL, tumour infiltrating lymphocytes; LN, nonsentinel lymph nodes; PBL, peripheral blood leukocytes. $\mathrm{ND}=$ Not determined. $-=$ Below background value. ${ }^{\mathrm{B}} \mathrm{BG}=$ Background, proliferation in complete medium, mean value from triplicate. ${ }^{\mathrm{b}} \mathrm{Peak}=$ The highest proliferation upon stimulation with autologous tumour extract, mean value from triplicate. ${ }^{\mathrm{C}} \mathrm{SI}=$ stimulation index = peak/BG. ${ }^{\mathrm{d}}$ Single high measurements without dose-response or antigen dependent kinetics.

detected, with the exception of three patients (no 6, 7 and 8) (Table 2). In PBLs the addition of tumour antigen did not result in vigorous proliferation in any case, but responses could be seen in patients no 7,13 and 14. In the nonsentinel node in patient 11 and in SN lymphocytes from patient 12, high proliferation indexes were obtained (Table 2). They represent single-point measurements, lacking the characteristic dose-response and/or kinetics of antigen-driven proliferation.

To further investigate the functional state of the lymphocytes, $\mathrm{T}$ cells were stimulated with Con A which by-pass the antigenspecific activation through the T-cell receptor. TILs were unresponsive to Con A stimulation, as were SN lymphocytes from Duke's C patients no 11-12. SN lymphocytes from the remaining patients proliferated vigorously, as did PBLs and nonsentinel node lymphocytes from both $\mathrm{C}$ and $\mathrm{D}$ patients (Figure $2 \mathrm{~A}$ and $\mathrm{B}$ ).

The ability of the lymphocytes to produce IFN- $\gamma$ when stimulated with antigen or with Con A was investigated in six patients, no 4, 5, 8, 13-15 (Table 3). Tumour-infiltrating lymphocytes from Duke's B patient no 4 secreted high amounts of IFN- $\gamma$ when stimulated with Con A $\left(717 \mathrm{pg} \mathrm{ml}^{-1}\right)$ and five times the background level upon addition of tumour extract, in spite of their inability to respond in the proliferation assay. Tumour-infiltrating lymphocytes from patient 5 (Duke's B) (Figure 3) and patient 15 (Duke's D) did not produce IFN- $\gamma$ when stimulated with tumour homogenate, nor when they were stimulated with Con A (data not shown). In patients 8,13 and 14 (Duke's C), the amount of TILs obtained, did not suffice for the IFN- $\gamma$ ELISA.

SN lymphocytes from Duke's B patients no 4, 5 (Figure 3A) and 8 , and from Duke's C patient no 13 (Figure 4B) secreted IFN- $\gamma$ 4-38 times above background level when stimulated with autologous tumour homogenate. In patients no 14 and $15 \mathrm{SN}$ lymphocytes did not produce IFN- $\gamma$ above background, upon stimulation with tumour homogenate. Lymphocytes from nonsentinel nodes did not respond with any IFN $-\gamma$ secretion above background levels (Figure $3 \mathrm{~A}$ ), with the exception of patient no 8 , where the secretion was 30 times the background level. In patients no 4 and 8 secretory responses of four to five times background level were seen in PBLs. SN-, nonsentinel lymphocytes and PBLs displayed a vigorous secretory response when stimulated with Con A (data not shown).

\section{DISCUSSION}

In this study we identify a localised immune response against autologous tumour extract in patients with colon cancer, by using an injection technique allowing for the identification of the tumour draining sentinel node (Figure 1A, right panel, Table 1). SN lymphocytes have been endogenously sensitised towards tumourderived antigens presented by professional antigen presenting cells and represent a naturally in vivo expanded population of cells that can be further multiplied and possibly used for immunotherapy.

Proliferation in sentinel nodes, displaying dose dependence and/ or kinetics of antigen dependence, was present in a majority of patients (Figure 1A, right panel, Table 2). Responses were of varying magnitude and tended to be weaker or absent in patients with metastatic sentinel nodes (Table 2 and Figure 1B). We have recently described proliferative responses against the autologous tumour in sentinel nodes draining urinary bladder cancers (Marits et al, 2006), further supporting the immunological value of the sentinel node detection method. In the three Duke's B patients no 6-8 dose-dependent proliferation was also detected in nonsentinel lymph nodes. In patients 6 and 8 these nodes were located on the predicted lymphatic drainage pathway from the tumour. In patient 7 , the exact anatomical location of the investigated nonsentinel lymph node could not be determined. However, all the 22 investigated lymph nodes in the pathological specimen were enlarged and displayed histological evidence of immune reactivity.

In six of the patients the IFN- $\gamma$ secretory response was investigated (Table 3 ). The IFN- $\gamma$ response correlated closely with the proliferative responses, with a few exceptions: In patient 4, TILs did produce IFN- $\gamma$, but they did not proliferate in response to the autologous tumour. The same applied to PBLs from this patient and PBLs from patient 8 . This possibly reflects a different state of effector differentiation in these cells than in lymph node acquired cells, exemplified by Duke's C patient no 13. Here, SN lymphocytes displayed vigorous, spontaneous proliferation which could be further augmented by the addition of tumour homogenate, possibly indicating an ongoing expansion of tumourspecific effector cells. By contrast, IFN- $\gamma$ secretion was strongly inducible by antigen stimulation but undetectable in unstimulated cultures (Figure 4). Factors influencing long-term tumour free survival following surgical resection of colon cancers are 
incompletely understood. Histological parameters indicating a Tcell mediated immune response in mesocolic lymph nodes have been found to correlate with increased survival rates (Patt et al,

A

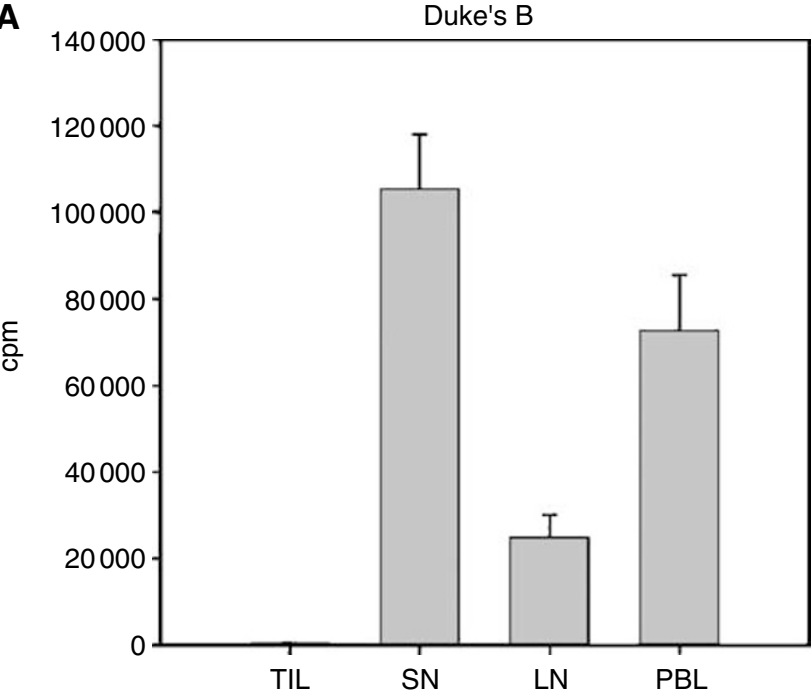

B

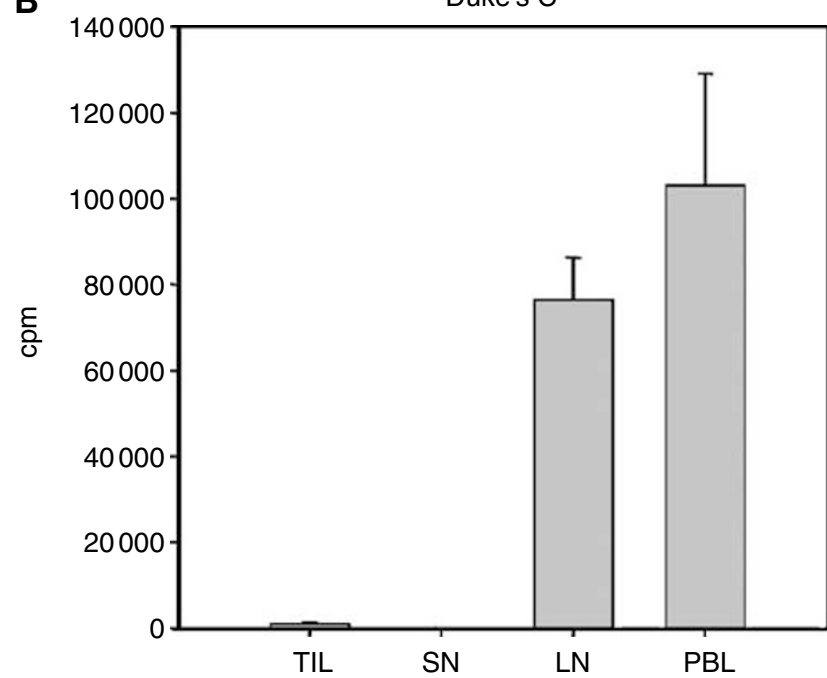

Figure 2 Proliferative responses against Con A. Tumour infiltrating lymphocytes (TIL), cells from sentinel node (SN), from nonsentinel lymph nodes (LN) and peripheral blood leucocytes (PBL), obtained from I 5 colon cancer patients were investigated with ${ }^{3} \mathrm{H}$-Thymidine incorporation upon stimulation with $10 \mu \mathrm{g} \mathrm{ml}^{-1}$ of ConA. Data from patient no 2 with a Duke's B tumour $(\mathbf{A})$ and patient no I I with a Duke's $C(\mathbf{B})$. Error bars indicate s.e.m.
1975). It is tempting to speculate that the strong immune response in patient no 13 is a predictor of survival. This will be addressed when follow-up data from the patients is available.

TILs displayed an activated $\mathrm{CD} 9^{+}$phenotype, similar to $\mathrm{SN}$ lymphocytes (Figure $1 \mathrm{~A}$ and $\mathrm{B}$ middle panels), but when tested against autologous tumour antigens (Figure $2 \mathrm{~A}$ and $\mathrm{B}$ right panels) or Con A (Figure 2A) they did not proliferate. In two metastatic sentinel nodes, from patients no 11 and 12 , the response against ConA was also blunted, indicating a state of tumour-induced immunosuppression. Some investigators (Hoon et al, 1987; O'Sullivan et al, 1996) have observed immunosuppression in regional lymph nodes also in the absence of lymph node metastases. This contrasts with our data, where SN lymphocytes in Duke's B patients responded adequately to the mitogen ConA (Figure 2B). This may reflect differences in the biology of the primary tumour, as indicated by the study by O'Sullivan et al (1996), who found evidence for immunosuppression in lymph nodes draining squamous cell carcinomas of the oesophagus but not in adenocarcinomas. Secretion of immunosuppressive factors from CRC cell lines has been reported previously (Luo et al, 1997). Fresh CRC specimens have been shown to express indoleamine 2,3-dioxygenase (IDO), an enzyme, which catalyses tryptophan degradation. Tryptophan depletion causes proliferative arrest of $\mathrm{T}$ cells and hampers local antitumour immunity in mouse models (Uyttenhove et al, 2003). In addition, chemokine-mediated recruitment of $\mathrm{CD} 4{ }^{+} \mathrm{CD} 25^{+} \mathrm{T}$ regulatory cells to the tumour bed, has recently been described in ovarial cancer (Curiel et al, 2004). The influence of $\mathrm{CD} 4{ }^{+} \mathrm{CD} 25^{+}$cells on immune responses against human colon cancers is under investigation in the laboratory.

Naturally induced, tumour-reactive $\mathrm{T}$ cells as measured with specific cytokine secretion in response to tumour antigens have been identified in blood in a subset of CRC patients albeit at a low frequency (Nagorsen et al, 2000). We detected proliferation in peripheral blood in the three Duke's $C$ patients no 7, 13 and 14 (Table 2), while PBLs from the other 12 patients were unresponsive. This is consistent with that the majority of these cells have not encountered tumour antigens and thus the precursor frequency of $\mathrm{T}$ cells in peripheral blood with a specific $\mathrm{T}$-cell receptor recognising tumour antigen(s) is low.

In a murine system, tumour sensitised but not fully functional, lymphocytes were identified in tumour draining lymph nodes. These cells could be converted into effector cells by in vitro expansion with anti-CD3mAB and IL-2 and were capable of mediating regression of established metastases following adoptive transfer (Yoshizawa et al, 1991). In human CRC; adoptive transfer of in vitro expanded lymph node cells, has been attempted in patients with advanced metastatic disease (Kim et al, 1999). The lymph nodes were identified by radioimmuno-guided surgery (RIGS) utilising a ${ }^{125} \mathrm{I}$ labelled monoclonal antibody against a mucin expressed by carcinomas, consequently dependent on the

Table 3 Production of IFN- $\gamma$ upon stimulation with autologous tumour extract.

\begin{tabular}{|c|c|c|c|c|c|c|c|c|c|c|c|c|}
\hline Pat nr & \multicolumn{3}{|c|}{ SN } & \multicolumn{3}{|c|}{ TIL } & \multicolumn{3}{|c|}{ LN } & \multicolumn{3}{|c|}{ PBL } \\
\hline 4 & 12 & 463 & 38,6 & 26 & 120 & 4,6 & 8 & 12 & 1,5 & 11 & 12 & 1,1 \\
\hline 5 & 30 & 107 & 3,7 & 13 & 13 & 1 & 10 & 13 & 1,3 & 7 & 7 & 1,0 \\
\hline 8 & 14 & 82 & 5,9 & ND & ND & ND & 62 & 688 & 11,0 & 16 & 93 & 5,8 \\
\hline 13 & 97 & 1806 & 18,6 & ND & ND & ND & ND & ND & ND & ND & ND & ND \\
\hline
\end{tabular}

SN, sentinel node; TIL, tumour infiltrating lymphocytes; LN, nonsentinel lymph nodes; PBL, peripheral blood leukocytes. ND = Not determined. ${ }^{\mathrm{a}} \mathrm{BG}=\mathrm{Background}$, secretion of IFN- $\gamma$ when cultured in complete medium alone, value from pooled triplicates. ${ }^{\text {b }}$ The highest amount of IFN- $\gamma$ secreted upon stimulation with autologous tumour extract, value from pooled triplicates. ${ }^{c} \mathrm{SI}=$ stimulation index $=$ peak/BG. 
A

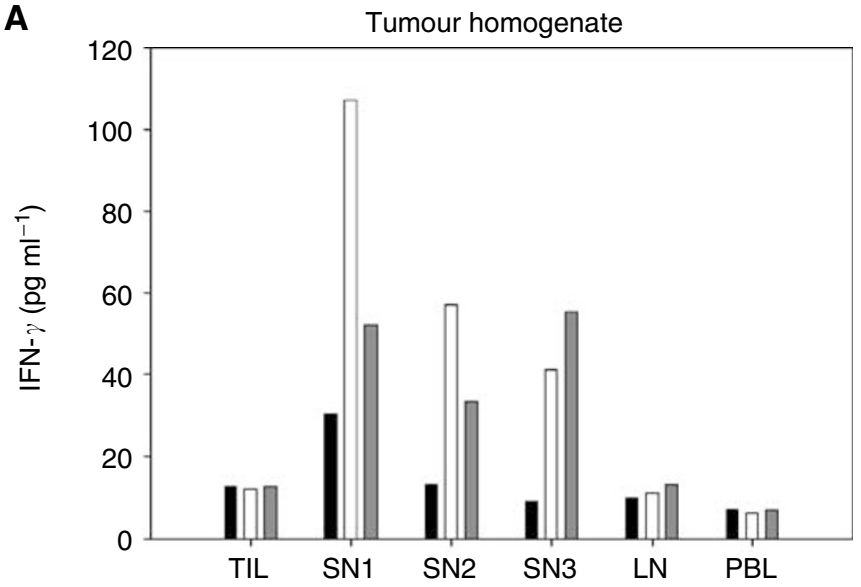

B

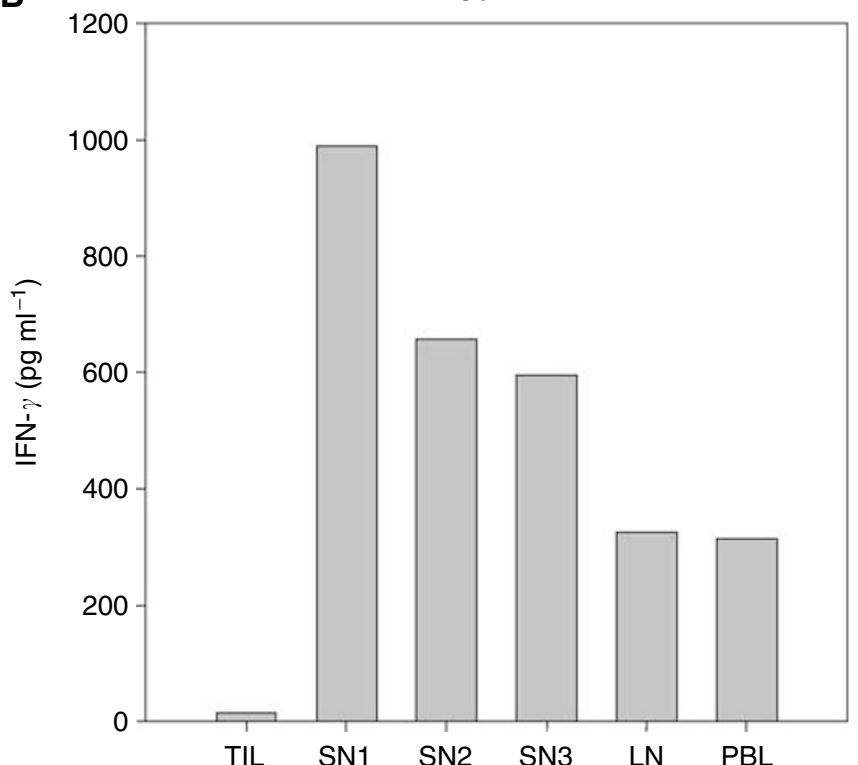

Figure 3 Stimulation with autologous tumour homogenate elicits IFN- $\gamma$ production in lymphocytes from sentinel node. In six of I 5 patients, IFN- $\gamma$ secretory responses were investigated with ELISA on culture supernatants. Tumour infiltrating lymphocytes (TIL), lymphocytes from sentinel nodes (SNI-3), from nonsentinel node (LN) and in peripheral blood leucocytes (PBL) from patient no 5, were cultured with medium alone (black bars), autologous tumour homogenate diluted I/I00 (open bars), I/I0 (grey bars) $(\mathbf{A})$ or ConA $10 \mu \mathrm{g} \mathrm{ml}^{-1}$ (B). The IFN- $\gamma$ production was measured in pooled triplicates of supernatants collected at day 5 .

presence of tumour cells or tumour-derived material in the nodes. In this study, one patient achieved a partial response and 4 patients (4/23) minor responses and an overall increase in survival was observed (Kim et al, 1999), indicating a role for immunotherapy in colon cancer. In comparison with the present work, we identify the sentinel node(s), which are the first lymph node(s) to drain the primary tumour, without the use of radioactivity or depending on the presence of specific tumour-derived epitopes in the node(s).

In summary, we demonstrate that freshly isolated lymphocytes from sentinel nodes in patients with established colorectal carcinoma mount proliferative responses against autologous tumour extract. These cells have not yet been exposed to the immunosuppressive milieu of the tumour and constitute an in vivo expanded source of tumour reactive lymphocytes. Instead of using TIL or peripheral blood lymphocytes, we propose sentinel nodederived lymphocytes as a source of enriched tumour reactive $\mathrm{T}$ cells, suitable for adoptive immunotherapy.
A

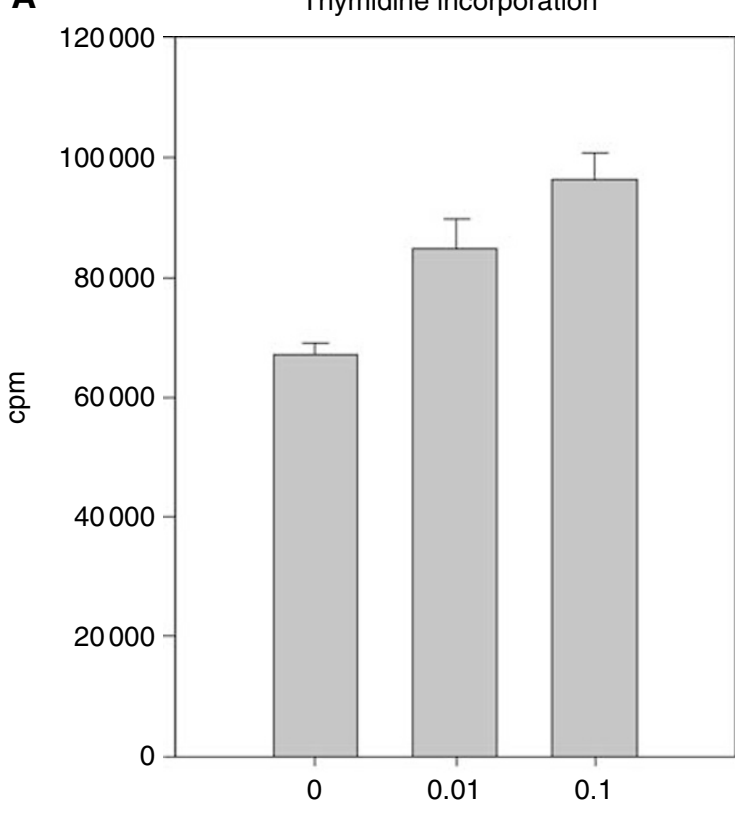

B

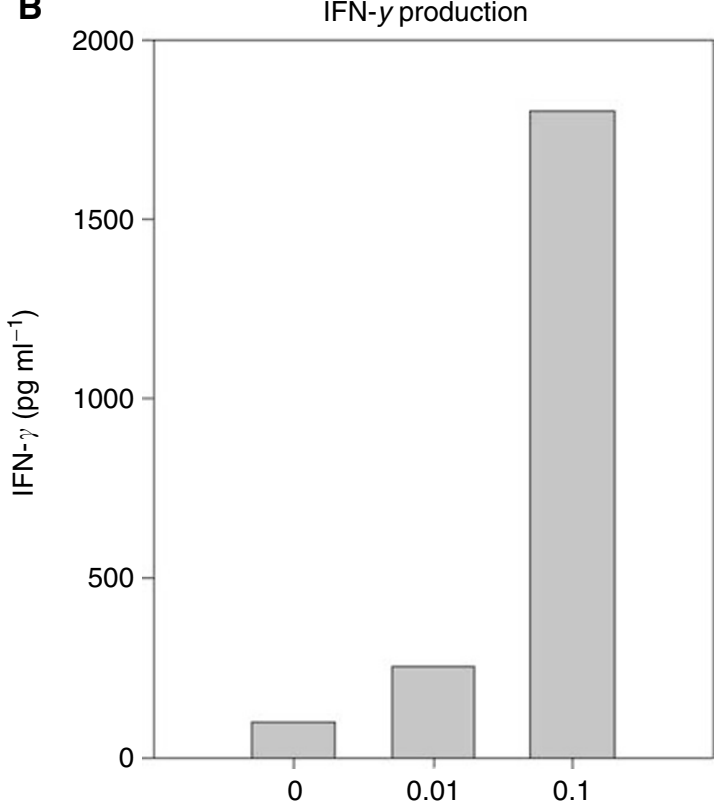

Figure 4 High spontaneous proliferation and specific IFN- $\gamma$ production upon addition of tumour homogenate in cells from a sentinel node in a case of Duke's C. In six of I 5 patients, IFN- $\gamma$ secretory responses investigated with ELISAs on culture supernatants. A single cell suspension from the sentinel node from patient no 13 was incubated with 10- and 100-fold dilutions of autologous tumour homogenate in a time course proliferation assay. Cells were pulsed with $\mid \mu C_{\mathrm{i}}{ }^{3} \mathrm{H}$-Thymidine, $18 \mathrm{~h}$ before harvesting. Error bars indicate s.e.m. (A). The corresponding IFN- $\gamma$ production by the sentinel node acquired lymphocytes was measured in an ELISA on pooled triplicates of supernatant collected day 7 (B).

\section{ACKNOWLEDGEMENTS}

This study was supported by the Swedish Cancer Society, the King Gustav V's Jubilee Foundation, the Lions Cancer foundation, the Lundberg Foundation, the Cancer and Allergy foundation, the Wiberg Foundation, the Hedlunds foundation and the Selander foundation. 


\section{REFERENCES}

Arkenau HT, Bermann A, Rettig K, Strohmeyer G, Porschen R (2003) 5-Fluorouracil plus leucovorin is an effective adjuvant chemotherapy in curatively resected stage III colon cancer: long-term follow-up results of the adjCCA-01 trial. Ann Oncol 14: 395-399

Benson III AB, Schrag D, Somerfield MR, Cohen AM, Figueredo AT, Flynn PJ, Krzyzanowska MK, Maroun J, McAllister P, Van Cutsem E, Brouwer M, Charette M, Haller DG (2004) American Society of Clinical Oncology recommendations on adjuvant chemotherapy for stage II colon cancer. J Clin Oncol 22: 3408-3419

Burnet FM (1970) The concept of immunological surveillance. Progr Exp Tumor Res 13: $1-27$

Cabanas RM (1977) An approach for the treatment of penile carcinoma. Cancer 39: $456-466$

Curiel TJ, Coukos G, Zou L, Alvarez X, Cheng P, Mottram P, EvdemonHogan M, Conejo-Garcia JR, Zhang L, Burow M, Zhu Y, Wei S, Kryczek I, Daniel B, Gordon A, Myers L, Lackner A, Disis ML, Knutson KL, Chen L, Zou W (2004) Specific recruitment of regulatory $\mathrm{T}$ cells in ovarian carcinoma fosters immune privilege and predicts reduced survival. Nat Med 10: $942-949$

Dahl K, Westlin J, Kraaz W, Winqvist O, Bergkvist L, Thorn M (2005) Identification of sentinel nodes in patients with colon cancer. Eur J Surg Oncol 31: $381-385$

Duke CE (1932) The classification of cancer of the rectum. J Pathol Bacteriol 35: $323-332$

Dunn GP, Old LJ, Schreiber RD (2004) The three e's of cancer immunoediting. Ann Rev Immunol 22: 329-360

Giorgio AD, Botti C, Tocchi A, Mingazzini P, Flammia M (1992) The influence of tumor lymphocytic infiltration on long term survival of surgically treated colorectal patients. Int Surg 77: 256-260

Hoon DS, Korn EL, Cochran AJ (1987) Variations in functional immunocompetence of individual tumor-draining lymp nodes in humans. Cancer Res 47: 1740-1744

Hom SS, Rosenberg SA, Topalian SL (1993) Specific immune recognition of autologous tumor by lymphocytes infiltrating colon carcinomas: analysis by cytokine secretion. Cancer Immunol Immunother 36: 1-8

Itano AA, Jenkins MJ (2003) Antigen presentation to naive CD4T cells in the lymph node. Nature Immunology 4: 733-739

Kim JA, Bresler HS, Martin EW, Aldrich W, Heffelfinger M, Triozzi PL (1999) Cellular immunotherapy for patients with metastatic colorectal carcinoma using lymph node lymphocytes localized in vivo by radiolabeled monoclonal antibody. Cancer 86: $22-30$

Leong SPL (2004) Paradigm of metastasis for melanoma and breast cancer based on the sentinel node experience. Ann Surg Oncol 11: 192s-197s

Luo JS, Kammerer R, Schultze H, Kleist SV (1997) Modulations of the effector function and cytokine production of human lymphocytes by secreted factors derived from colorectal-carcinoma cells. Int J Cancer 72: $142-148$

Marits P, Karlsson M, Sherif A, Garske U, Thorn M, Winqvist O (2006) Detection of immune responses against urinary bladder cancer in sentinel lymph nodes. Eur Urol 49: 59-70
Nagorsen D, Keilholz U, Rivoltini L, Schmittel A, Letsch A, Asemissen AM, Berger G, Buhr HJ, Thiel E, Scheibenbogen C (2000) Natural T-cell response against MHC class I epitopes of epithelial cell adhesion molecule, her-2/neu and carcinoembryonic antigen in patients with colorectal cancer. Cancer Res 60: 4850-4854

Nakagomi H, Petersson M, Magnusson I, Juhlin C, Matsuda M, Mellstedt H, Taupin JL, Vivier E, Andersson P, Kiessling R (1993) Decreased expression of the signal-transducing zeta chains in tumor-infiltrating T-cells and NK cells of patients with colorectal carcinoma. Cancer Res 53: $5610-5612$

Obrand DI, Gordon PH (1997) Incidence and patterns of recurrence following curative resection for colorectal carcinoma. Dis Colon Rectum 40: $15-24$

O'Sullivan GC, Corbett AR, Shanahan F, Collins JK (1996) Regional immunosuppression in esophageal squamous cancer: evidence from functional studies with matched lymph nodes. J Immunol 157: 4717-4720

Parkin DM, Bray F, Ferlay J, Pisani P (2005) Global cancer statistics, 2002. CA Cancer J Clin 55: 74-108

Patt DJ, Brynes RK, Vardiman JW, Coppleson LWW (1975) Mesocolic lymph node histology is an important prognostic indicator for patients with carcinoma of the sigmoid colon: an immunomorphologic study. Cancer 35: $1388-1397$

Ribas A, Butterfield LH, Glaspy JA, Economou JS (2003) Current developments in cancer vaccines and cellular immunotherapy. J Clin Oncol 21: 2415-2432

Rigg KM, Brotherick I, Tayolor RMR, Lennard TWJ (1991) Alterations in circulating lymphocyte number and function after circulation through colorectal carcinomas. Surgery 109: $747-755$

Rosenberg SA (2001) Progress in human tumour immunology and immunotherapy. Nature 411: $380-384$

Rosenberg SA, Dudley ME (2004) Cancer regression in patients with metastatic melanoma after the transfer of autologous antitumor lymphocytes. Proc Natl Acad Sci USA 101: 14639-14645

Saha SWD, Badin J, Beutler T, Nora D, Ganatra BK, Desai D, Kaushal S, Nagaraju M, Arora M, Singh T (2000) Technical details of sentinel lymph node mapping in colorectal cancer and its impact on staging. Ann Surg Oncol 7: $120-124$

Swanson RS, Compton CC, Stewart AK, Bland KI (2003) The prognosis of T3N0 colon cancer is dependent on the number of lymph nodes examined. Ann Surg Oncol 10: 65-71

Thörn M (2000) Lymphatic mapping and sentinel node biopsy: is the method applicable to patients with colorectal and gastric cancer? Eur J Surg 166: $755-758$

Uyttenhove C, Pilotte L, Theate I, Stroobant V, Colau D, Parmentier N, Boon T, Van den Eynde BJ (2003) Evidence for a tumoral immune resistance mechanism based on tryptophan degradation by indoleamine 2,3-dioxygenase. Nat Med 9: 1269-1274

Yoshizawa H, Chang AE, Shu S (1991) Specific adoptive immunotherapy mediated by tumor-draining lymph node cells sequentially activated with anti-CD3 and IL-2. J Immunol 147: 729-737 